\title{
Frontières
}

GAGNON, Marie, Lettres de prison, Montréal, VLB Éditeur, 2002, 188 p.

\section{Stéphane Thibault}

Volume 16, numéro 1, automne 2003

URI : https://id.erudit.org/iderudit/1073774ar

DOI : https://doi.org/10.7202/1073774ar

Aller au sommaire du numéro

Éditeur(s)

Université du Québec à Montréal

ISSN

1180-3479 (imprimé)

1916-0976 (numérique)

Découvrir la revue

Citer ce compte rendu

Thibault, S. (2003). Compte rendu de [GAGNON, Marie, Lettres de prison, Montréal, VLB Éditeur, 2002, 188 p.] Frontières, 16(1), 101-101.

https://doi.org/10.7202/1073774ar

Ce document est protégé par la loi sur le droit d'auteur. L'utilisation des services d'Érudit (y compris la reproduction) est assujettie à sa politique d'utilisation que vous pouvez consulter en ligne.

https://apropos.erudit.org/fr/usagers/politique-dutilisation/
Cet article est diffusé et préservé par Érudit.

Érudit est un consortium interuniversitaire sans but lucratif composé de l’Université de Montréal, l'Université Laval et l'Université du Québec à Montréal. Il a pour mission la promotion et la valorisation de la recherche. https://www.erudit.org/fr/ 
L'auteure nous présente avec cet ouvrage sa troisième publication faisant suite à Bienvenue dans mon cauchemar (1997) et Les héroïnes de Montréal (1999). À la rencontre de I'art littéraire et d'un discours descriptif/ informatif sur la vie en milieu carcéral, ces deux genres se retrouvent, dans des proportions variant selon l'humeur du jour de l'auteure, dans l'ensemble de ces lettres qui deviennent ainsi plus qu'une simple correspondance.

L'art littéraire constitue pour l'auteure le moyen de prédilection pour extraire d'une expérience fondamentalement négative la force de supporter l'épreuve qui se présente à elle. "Voilà pourquoi je vis, J.-Y. : pour la petite prose qui précède. Pour la composer, j'ai plongé dans le chaos, et pourtant me font mal le bruit et la fureur. Le mal existe loin du silence et j'habite le bruit. Plus je me noierai dans les abîmes, plus je saurai écrire le ciel » (p. 12).

Nous accompagnons ainsi sur le chemin une écrivaine qui se cherche dans les mots, afin d'y trouver la route qui constituera sa voie de sortie. « J'aimerais que mon style se précise, se raffine au point d'épouser parfaitement le cri qui m'habite " (p. 20). Une telle tâche n'est toutefois pas des plus faciles dans un tel milieu et exige un effort soutenu au quotidien afin d'éviter de se perdre en route: " Il pleut des souvenirs sur un coin d'horizon, entre les mailles du grillage. Derrière, des barreaux. Ils me blessent. Ma vie est un parapluie dont je ne vois plus que l'envers. Les ondées m'atteignent de plein fouet et je désire me noyer " (p. 104); "J'ai peine à me lever, peine à $m$ 'habiller, peine à marcher. Et toi qui me demandes d'écrire ! J'ai la peine du pen. Comprendra qui pourra » (p. 161).

C'est donc à l'aide de l'art littéraire que Marie Gagnon tentera de peindre un portrait du milieu qui l'entoure, portrait destiné à une société qui maintient un voile devant la « vraie » réalité carcérale pour préserver la douceur de l'ignorance: « Je dirai le laid et l'odieux que les gens de bien se cachent pour ne pas réveiller leur conscience, mais aussi le beau, car en chaque femme qu'on emprisonne, il y a de la beauté » (p. 89).

Le thème principal qui se dégage de ce tableau est la détresse psychologique vécue à l'intérieur des murs de la Maison Tanguay et du pénitencier de Joliette. Toutefois, contrairement à ce que certains pourraient croire, ce n'est pas tant le milieu carcéral lui-même, où règne une certaine solidarité entre détenues, qui est la cause principale de cette détresse décrite par l'auteure. Bien que les bassesses du milieu demeurent un facteur, l'auteure a plutôt choisi les abus de la psychologie pour en faire son cheval de bataille:

Je ne trame aucune émeute, mais je veux dire ce qui est. Je veux mettre de l'ordre et du sens là où règnent le désordre et la déraison. Je veux renseigner les gens sensibles et intelligents sur la réalité de la prison. Rares sont ceux qui en ont une juste perception. Je veux qu'on sache que si l'abus de pesticides peut s'avérer dangereux pour la santé physique, un excès de psychologie peut rendre fou à lier (p. 162).

Tanguay change, donc, et pas nécessairement pour le mieux. [...] Il y a aussi que les symptômes d'une terrible maladie commencent à s'y manifester. Cette maladie se nomme psychosociologie. Elle s'attaque à l'âme. [...] La psychosociologie marque du sceau de la suspicion tous ceux qu'elle afflige. De malade à soigner, le patient devient phénomène à étudier et suspect à confondre (p. 91-92) Ici [pénitencier de Joliette], on veut tellement ton bien qu'on te plonge en enfer (p. 128).

L'auteure se questionne par ailleurs sur le bien-fondé de modèles théoriques qui lui paraissent mal adaptés à la pratique :

Comment a-t-on pu croire au départ que la détention dans un centre carcéral pouvait se combiner avec une thérapie? La première implique la défensive alors que la thérapie exige de la transparence et de la confiance réciproque. Les deux sont tout simplement incompatibles et dangereuses [...] (p. 187). La psychologie, je ne la vois pas comme une science. C'est un art. En science, les règles s'appliquent partout de la même manière.

Pas en art. La psychologie conçue comme une science, c'est comme de la peinture académique : laid (p. 169). On m'a mise en prison pour cause de crimes, non de maladie. Pourquoi me soigner? Et si mes délits étaient causés par une maladie, pourquoi $\mathrm{m}^{\prime} \mathrm{empri}-$ sonner alors? (p. 149).

C'est ainsi que la question identitaire surgit dans un milieu dont l'objectif premier est de normaliser les comportements par la transformation de l'individu:

Je veux à la fois rester moimême et rester dans la légalité.

C'est possible malgré ce que m'ont ressassé un tas de psychologues à la manque, ces dernières années. La passion attire les ennuis, c'est vrai. Mais je suis un être de passion et le resterai. Passion vaut mieux que tiédeur. Il est possible que je demeure fidèle à ce qui a inspiré mon

passé sans, pour autant, commettre de nouveaux délits (p. 82).

De ce passé, Marie Gagnon a donc choisi d'en tirer l'inspiration essentielle à sa nouvelle profession et de donner à l'aide de cet ouvrage un refuge à son indignation: «[...] Je ne suis plus que rébellion. Je ne me sens d'aucune ville, d'aucun pays, d'aucun groupe social. Ma contrée, c'est l'écriture ; mon village, les mots » (p. 80).

Stéphane Thibault 